\title{
Analytical methods of optimization of operational parameters of the main gas pipelines (gas mains)
}

\author{
Frolov V., Pyanylo Ya., Prytula M. \\ Centre of Mathematical Modelling of Pidstryhach Institute for \\ Applied Problems of Mechanics and Mathematics NAS of Ukraine, \\ 15 Dudayev Str., 79005, Lviv, Ukraine; \\ Institute of Gas Transmission PJSC Ukrtransgas, \\ 16 Marshal Konev Str., 61004, Kharkiv, Ukraine
}

(Received 15 January 2018)

\begin{abstract}
An analytical model for the operation of the main gas pipeline is proposed. The results of the investigation of the domain of optimality by analytical methods are presented. The developed software is tested on real data. Comparative results of modeling and optimization by numerical and analytical methods are presented.
\end{abstract}

Keywords: gas transportation system, optimization, optimal mode, compressor station.

2000 MSC: $76 \mathrm{~N} 25,49 \mathrm{~J} 20$

UDC: $622.692 .4+622.691 .24$

DOI: $10.23939 / \mathrm{mmc} 2018.01 .001$

\section{Introduction}

The tasks of modeling and optimizing of gas flows in main gas pipelines are widely used by the dispatching units of gas transportation systems. The development of optimal operating modes is one of the most effective methods for the reducing the natural gas transportation costs. The task of optimizing the operation of main gas pipelines is complicated by the cumbersome nature of the subject, nonlinearity and discreteness of its characteristics, and the existence of a plurality of different types of constraints. Typically, the selective method of Belman's dynamic programming [1] and its modifications for the case of several system state parameters with successive approximations, as a rule, is used to solve optimization problems of the modes of individual gas mains (GM). Among the modifications, the method of step variations, the Danzig-Wulff method, and the discrete principle of maximum should be noted [2]. Other approaches to the main gas pipelines operating parameters optimization are being also developed, namely integral, gradient methods and their modifications, etc. [3-5]. Those or other methods are oriented to take into account certain structural features of the gas transportation system (GTS) and therefore it complicates their efficiency comparison.

Despite the richness of various methods and algorithms, there are no generally accepted approaches to the optimization of GTS operational mode parameters, and even more, there are no implemented and tested software complexes for the industrial use [6-11].

The creation of effective methods of optimization should be preceded by the study of the domain of optimality, which will allow more purposeful search for extreme mode GM parameters, and significantly reduce the optimality domain for the sampling methods. For these purposes, the most effective are analytical methods that can reliably ensure that the global extremes of the investigated criteria of optimality are found. The purpose of this work is to obtain precise and qualitative results of the investigated criteria of optimality of main gas pipelines, which will significantly reduce the complexity of the algorithmic and ensure the creation of high-performance software. 


\section{Modeling of compressor station operation modes}

The model of the compressor station (CS) is formed on the basis of the technological scheme structure model and its functional objects models, which directly affect the value of the operational parameters. The structure model is represented as a graph in which objects that have a length are represented by edges, and all others are vertices. In the main object (gas-pumping unit (GPU)) two main components are distinguished (drive and centrifugal supercharger $(\mathrm{CeS})$ ). In this work, gas turbine type drives are considered. It is well-known [12] that the gas parameters at the input and output of the CeS are related via a set of empirical dependencies

$$
\begin{gathered}
\varepsilon=\varphi_{1}\left([q]_{p r},\left[\frac{n}{n_{n}}\right]_{p r}\right), \quad \eta_{p o l}=\varphi_{2}\left([q]_{p r}\right), \quad \frac{N_{i}}{\gamma_{n}}\left(\frac{n_{n}}{n}\right)^{3}=\varphi_{3}\left([q]_{p r}\right), \\
N_{e}^{p}=N_{e}^{n} K_{N e}\left(1-K_{t} \frac{t_{0}-t_{0}^{n}}{t_{0}+273}\right) \frac{p_{a}}{0.1033}, \quad\left[\frac{n}{n_{n}}\right]_{p r}=\frac{n}{n_{n}} \sqrt{\frac{z_{p r} R_{p r} T_{p r}}{z R T}}, \quad[q]_{p r}=\frac{n_{n}}{n} q .
\end{gathered}
$$

The amount of fuel gas is based on the formula

$$
q_{p}=q_{p}^{n} K_{t}\left(0.75 \frac{N_{e}}{N_{e}^{n}}+0.25 \sqrt{\frac{t_{0}+273}{t_{0}^{n}+273} \frac{p_{a}}{0.1033}}\right),
$$

where

$$
q_{p}^{n}=\frac{860 N_{e}^{n}}{\eta_{e}^{n} Q_{n} 10^{3}}, \quad N_{e}=N_{i}:\left(\eta_{m} K_{N}\right)
$$

$n$ is the CeS rotation speed, $q$ is the CeS gas consumption, $\eta_{p o l}$ is the CeS polytrophic efficiency, $q_{p}, q_{p}^{n}$ is the real and nominal consumption of fuel gas, $\varepsilon$ is the pressure differential, $N_{e}^{n}$ is the nominal power of the gas turbine unit (GTU); $K_{N e}$ is the coefficient of technical state of gas turbine unit (GTU); $K_{t}$ is the coefficient, which takes into account the influence of temperature of atmospheric air; $t_{0}$ is the GTU entry air temperature; $t_{0}^{n}$ is the nominal GTU entry air temperature; $p_{a}$ is the absolute pressure of atmospheric air, depending on altitude above sea level $\mathrm{H} ; t_{0}$ is the GTU entry air temperature $\left({ }^{\circ} \mathrm{C}\right)$, $N_{i}$ is the internal CeS power; $Q_{n}$ is the nominal lower specific volumetric heat of fuel combustion, $\eta_{e}^{n}$ is the nominal GTU efficiency, $\eta_{m}$ is the mechanical efficiency, $K_{N}$ is the technical state by power, $z_{p r}, R_{p r}, T_{p r}$ are gas parameters at which the characteristics of the supercharger are experimentally determined; $\gamma_{\mathrm{c}}$ is the specific weight of gas at standard conditions $(P=0.1033 \mathrm{MPa} ; T=293 \mathrm{~K}) ; n_{n}$ is the nominal CeS rotation speed, $\varphi_{k}(k=1-3)$ are empirically determined functions.

The given characteristics allow considering: the deviation of gas parameters at the entry of the supercharger $\left(z_{2 E}, R, T_{2 E}\right)$ from their reduced values $\left(z_{p r}, R_{p r}, T_{p r}\right)$, the deviation of the actual speed $n$ of the supercharger from its nominal $n_{n}$ value.

The value of polytrope is from the ratio $T_{o u t} z_{o u t}=T_{i n} z_{i n} \varepsilon^{\frac{k-1}{k \cdot \eta_{p o l}}}$ and specified using, with known ones $\varepsilon$ and $n$, the formula

$$
\varepsilon^{\frac{k-1}{k \eta_{p o l}}}=\left(\frac{n}{n_{n}}\right)^{2} \frac{z_{p r} T_{p r} R_{p r}}{z_{i n} T_{i n} R}\left(\varepsilon_{n}^{\frac{k-1}{k \eta_{p o l}}}-1\right)+1 .
$$

To calculate the internal power of the centrifugal supercharger, we use the known formula $[12,13]$

$$
N_{i}=\left(\frac{n}{n_{n}}\right)^{3} \rho \frac{m z_{p r} T_{p r} R_{p r} q_{p r}}{(m-1) \eta_{p o l} 60}\left(\varepsilon_{n^{\frac{m-1}{m}}}-1\right)
$$

where $m$ is a polytrophic coefficient. 
There is a set of technological constraints on the following: the position of the working points on the characteristics of $\mathrm{CeS}$ to ensure the operation of the GPU without surging; maximum volumetric CeS efficiency; frequency of the CeS shaft rotation $\left(n_{\min } \leqslant n \leqslant n_{\max }\right)$; maximum GTU power of GPU; maximum CeS exit pressure, which is determined by the durability of pipelines at the exit of CeS; maximum temperature at exit of $\mathrm{CeS}$, determined by the insulation of pipelines; minimum pressure value at the exit of each CeS; conditions related to the set of GPU operation stability level (distance from the surging zone); conditions of consistency of the scheme of CeS connection with the entry and exit loops.

\section{Polytropic work of gas compression at compressor stations at the conditions of fixed accumulated gas volume in the system}

We consider one-line gas main pipeline with three operating compressor stations, which are connected by two sections of pipeline (Fig. 1).

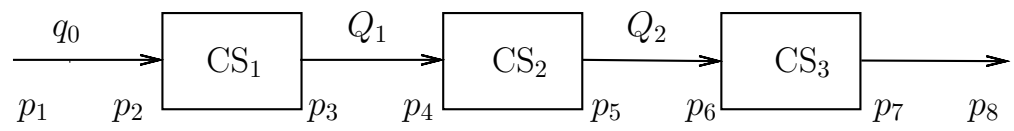

Fig. 1. Linear pipeline scheme.

We will conduct a study of the effect of the volumes of accumulated gas at the sections of the gas pipeline and the distribution of fuel gas consumption between the CS on the total energy costs with the following restrictions and given input data. It is believed that the indicators of:

- volumes of accumulated gas at the sections of the gas pipeline is constant, i.e.

$$
Q=Q_{1}+Q_{2}, \quad Q_{1}=\text { const }, \quad Q_{2}=\text { const; }
$$

- entry $p_{2}$ and exit $p_{7}$ pressures are constant;

- volumetric gas consumption $q_{0}$ at the system entry is constant;

- exit volumetric consumption $q_{v}$ is changing depending on the fuel gas volumetric consumption;

- indicator of CS work is determined by the pressure differentials $\varepsilon_{i}, i=1,2,3$, summary polytropic gas compression work.

Task formulation. Find the following values of gas compression coefficients $\varepsilon_{i}, i=1,2,3$ at compressor stations, which achieve a minimum total polytropical operation of gas compression $N_{\min }$ and follow the imposed restrictions.

Task solution. Under the defined gas flow mode the values of the pressure at the entries and exits of pipelines sections and compressor stations are connected by correlations:

$$
\begin{gathered}
p_{3}=\varepsilon_{1} p_{2} ; \\
p_{3}^{2}-p_{4}^{2}=\varkappa_{1} ; \\
p_{4}=\varepsilon_{2} p_{5} ; \\
p_{5}^{2}-p_{6}^{2}=\varkappa_{2} ; \\
p_{7}=\varepsilon_{3} p_{6} .
\end{gathered}
$$

Here the pipeline parameter $\kappa_{i}$, defined according to the formula

$$
\varkappa_{i}=\frac{\lambda_{i} z_{i} R T_{i}}{2 D_{i}}\left[\frac{4 \rho_{0}\left(q_{0}-\sum_{i=1}^{3} \Delta q_{i}\right)}{\pi D_{i}^{2}}\right]^{2},
$$

where $i$ is the pipeline section number,

Mathematical Modeling and Computing, Vol. 5, No. 1, pp. 1-9 (2018) 
Note that for $i=1-\Delta q_{1}=0$. Polytropic gas compression work at compressor station is calculated by the formula

$$
N=\frac{g \rho_{0} q}{102} \frac{k}{k-1} z R T\left(\varepsilon^{(k-1) / k \eta}-1\right) .
$$

Correlations (2)-(6) provide the opportunity to connect the values of entry and exit pressures between each other

$$
p_{7}^{2}=\varepsilon_{1}^{2} \varepsilon_{2}^{2} \varepsilon_{3}^{2} p_{2}^{2}-\varkappa_{1} \varepsilon_{2}^{2} \varepsilon_{3}^{2}-\varkappa_{2} \varepsilon_{3}^{2}
$$

If we introduce the indication

$$
l_{1 i}=\frac{2 \pi l_{i} D_{i}^{2}}{12 z_{i} R T}
$$

then the volumes of gas accumulated at the sections of pipeline are calculated by the formulas

$$
\begin{gathered}
Q_{1}=l_{11}\left(\varepsilon_{1} p_{2}+\frac{\varepsilon_{1}^{2} p_{2}^{2}-\varkappa_{1}}{\varepsilon_{1} p_{2}+\sqrt{\varepsilon_{1}^{2} p_{2}^{2}-\varkappa_{1}}}\right), \\
Q_{2}=l_{12}\left(\varepsilon_{2} \sqrt{\varepsilon_{1}^{2} p_{2}^{2}-\varkappa_{1}}+\frac{\varepsilon_{2}^{2}\left(\varepsilon_{1}^{2} p_{2}^{2}-\varkappa_{1}\right)-\varkappa_{2}}{\varepsilon_{2} \sqrt{\varepsilon_{1}^{2} p_{2}^{2}-\varkappa_{1}}+\sqrt{\varepsilon_{2}^{2}\left(\varepsilon_{1}^{2} p_{2}^{2}-\varkappa_{1}\right)-\varkappa_{2}}}\right) .
\end{gathered}
$$

Herewith the summary polytropic gas compression work of compressor stations of given system is defined as follows:

$$
N=\rho_{1} R\left(\theta_{1} q_{1} \frac{T_{0}\left(\varepsilon_{1}^{\nu_{1}}-1\right)}{1+f_{0} p_{2}}+\theta_{2} q_{2} \frac{T_{2}\left(\varepsilon_{2}^{\nu_{2}}-1\right)}{1+f_{2} \sqrt{\varepsilon_{1}^{2} p_{2}^{2}-\varkappa_{1}}}+\theta_{3} q_{3} \frac{T_{4}\left(\varepsilon_{3}^{\nu_{3}}-1\right)}{1+f_{4} \sqrt{\varepsilon_{2}^{2}\left(\varepsilon_{1}^{2} p_{2}^{2}-\varkappa_{1}\right)-\varkappa_{2}}}\right) .
$$

In the last formula we have introduced the indication

$$
\theta=\frac{k}{k-1}, \quad \nu=\frac{1}{\theta \eta}, \quad \rho_{1}=\frac{g \rho_{0}}{102} .
$$

The variable parameters in this task are the coefficients of gas compression at three compressor stations, and the constants are the volume of accumulated gas in the gas pipeline sections. It is obvious that in order to study the effect of compression coefficients on the energy costs of gas transportation, it is desirable to have an analytical solution of the formulated problem. Since the problem is nonlinear and it is not always possible to obtain an analytic solution, therefore, in our case, we confine ourselves to the first two units of the expansion in formulas (10) and (11). Then the following formulas are obtained for determining the volume of accumulated gas in the both gas pipeline sections

$$
Q_{1}=l_{11}\left(\varepsilon_{1} p_{2}+\frac{\varepsilon_{1}^{2} p_{2}^{2}-\varkappa_{1}}{\varepsilon_{1} p_{2}+\sqrt{\varepsilon_{1}^{2} p_{2}^{2}-\varkappa_{1}}}\right) .
$$

After certain transformations using asymptotic expansions in the first approximation we obtain that

$$
Q_{1}=\frac{3}{2} l_{11} \varepsilon_{1} p_{2}\left(1-\frac{5}{12} \frac{\varkappa_{1}}{\varepsilon_{1}^{2} p_{2}^{2}}\right)
$$

In the same way, to determine the volume of accumulated gas in the second section of the gas pipeline, the following formula is obtained

$$
Q_{2}=\frac{3}{2} l_{12} \varepsilon_{2} \varepsilon_{1} p_{2}\left(1-\frac{\varkappa_{1}}{2 \varepsilon_{1}^{2} p_{2}^{2}}-\frac{\varkappa_{2}}{4 \varepsilon_{1}^{2} p_{2}^{2} \varepsilon_{2}^{2}}\right) .
$$


Then the total volume of accumulated gas at the sections of the gas pipeline is calculated by the formula

$$
Q=\frac{3}{2} \varepsilon_{1} p_{2}\left[l_{11}\left(1-\frac{5}{12} \frac{\varkappa_{1}}{\varepsilon_{1}^{2} p_{2}^{2}}\right)+l_{12} \varepsilon_{2}\left(1-\frac{\varkappa_{1}}{2 \varepsilon_{1}^{2} p_{2}^{2}}-\frac{\varkappa_{2}}{4 \varepsilon_{1}^{2} p_{2}^{2} \varepsilon_{2}^{2}}\right)\right],
$$

or in the first approximation

$$
Q=\frac{3}{2} \varepsilon_{1} p_{2}\left(l_{11}+l_{12} \varepsilon_{2}\right)
$$

where

$$
\varepsilon_{1}=\frac{2 Q}{3 p_{2}\left(l_{11}+\varepsilon_{2} l_{12}\right)} .
$$

From the formula (9) we define the gas pressure differential for the third CS

$$
p_{7}^{2}=\varepsilon_{3}^{2}\left(\varepsilon_{1}^{2} \varepsilon_{2}^{2} p_{2}^{2}-\varkappa_{1} \varepsilon_{2}^{2}-\varkappa_{2}\right),
$$

where

$$
\varepsilon_{3}=\frac{p_{7}}{\sqrt{\varepsilon_{1}^{2} \varepsilon_{2}^{2} p_{2}^{2}-\varkappa_{1} \varepsilon_{2}^{2}-\varkappa_{1}}} .
$$

Substituting the values $\varepsilon_{1}$ and $\varepsilon_{3}$ in the formula (12), we obtain the dependence of the summary polytropical gas compression work by compressor stations only on the pressure differential of the second $\mathrm{CS}$, that is, one-parameter optimization task is obtained

$$
\begin{aligned}
& N\left(\varepsilon_{2}\right)=\rho_{1} R\left\{\theta_{1} q_{1} \frac{T_{0}}{1+f_{0} p_{2}}\left(\left(\frac{b}{l_{11}+\varepsilon_{2} l_{12}}\right)^{\nu_{1}}-1\right)+\theta_{2} q_{2} \frac{T_{2}\left(\varepsilon_{2}^{\nu_{2}}-1\right)}{1+f_{2} \sqrt{p_{2}^{2}\left(\frac{b}{l_{11}+\varepsilon_{2} l_{12}}\right)^{2}-\varkappa_{1}}}\right.
\end{aligned}
$$

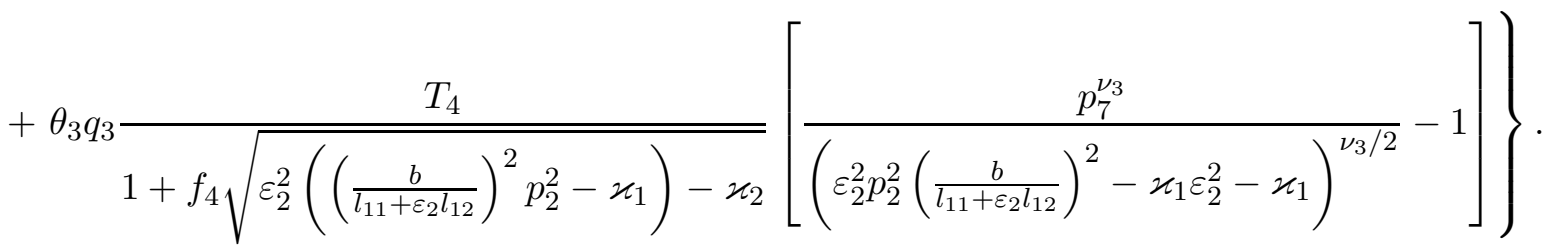

Here $b=2 Q / 3 p_{2}$.

The following algorithm for the calculation of above system optimal parameters is proposed.

1. We calculate the indicator of pressure differential $\varepsilon_{2}$ from the condition of function minimum $N\left(\varepsilon_{2}\right)$ (formula (15)).

2. By the formulas (13) and (14) we calculate the values of first and second CS pressure differentials.

From the conducted analysis it follows that the two imposed restrictions exclude consideration of the total two CS capacity minimizing - the first and third CS. Similarly, other CSs can be excluded.

Since the CS power, and thus the volumes of the used fuel gas, are nonlinear with respect to the pressure differentials, then a non-uniform solution should be expected. In the process of analysis of the solution (local extremes) we select the one that provides the minimum of fuel gas.

From the conducted study, it follows that if the number of CSs $n$ is greater than the number of constraints $m$, then $n-m$ values of the pressure differentials are based on the minimization of the total capacity function from these coefficients.

The solution obtained in this way is approximate, since asymptotic formulas were used to determine the total volume of accumulated gas in two sections of the pipeline. However, to analyze the impact of gas pressure differentials on energy costs, this is enough. Obviously, in order to determine the values of gas pressure differentials more accurately for energy costs optimization, it is necessary to formulate an appropriate optimization task in a nonlinear formulation. 


\section{Calculation of extreme parameters of main gas pipeline operation with gas turbine GPU at CS}

In the same way as in the previous paragraph, the main gas pipeline, which consists of three operating CSs and sections of the gas pipeline between them (Fig. 1), is considered.

If $p_{i}$ is the pressure value at $i$-th point, and $a_{i j}$ is calculated by the formula

$$
a_{i j}=\frac{\lambda_{i j} z_{i j} R T_{i j} l_{i j}}{D_{i j}}\left(\frac{\rho_{0}}{S_{i j}}\right)^{2},
$$

then in the case of steady gas flow mode we have the correlation $[12,13]$

$$
p_{i}^{2}-p_{j}^{2}=a_{i j} q_{0}^{2}
$$

Considering the formula (17) and gas pressure differential dependency $\varepsilon$ CS on the entry $p_{v x}$ and exit $p_{v y x}$ pressures $\left(\varepsilon=p_{v y x} / p_{v x}\right)$, then following dependencies take place for the studied system:

$$
\begin{aligned}
& p_{3}=\varepsilon_{1} p_{2} \\
& p_{4}^{2}=\varepsilon_{1}^{2}\left[p_{1}^{2}-a_{12}\left(q_{0}-q_{p 1}\right)^{2}\right]-a_{34}\left(q_{0}-q_{p 1}-q_{p 2}\right)^{2} \\
& p_{5}=\varepsilon_{2} p_{4} \\
& p_{6}^{2}=\varepsilon_{2}^{2}\left\{\varepsilon_{1}^{2}\left[p_{1}^{2}-a_{12}\left(q_{0}-q_{p 1}\right)^{2}\right]-a_{34}\left(q_{0}-q_{p 1}-q_{p 2}\right)^{2}\right\}-a_{56}\left(q_{0}-q_{p 1}-q_{p 2}-q_{p 3}\right)^{2} \\
& p_{7}=\varepsilon_{3} p_{6} .
\end{aligned}
$$

Then we obtain the following connection between the values of starting and ending pressures and gas pressure differentials

$$
\begin{aligned}
p_{8}^{2}=\varepsilon_{3}^{2}\left\{\varepsilon_{2}^{2}\left\{\varepsilon_{1}^{2}\left[p_{1}^{2}-a_{12}\left(q_{0}-q_{p 1}\right)^{2}\right]-a_{34}\left(q_{0}-q_{p 1}-q_{p 2}\right)^{2}\right\}\right. & \left.-a_{56}\left(q_{0}-q_{p 1}-q_{p 2}-q_{p 3}\right)^{2}\right\} \\
& -a_{78}\left(q_{0}-q_{p 1}-q_{p 2}-q_{p 3}\right)^{2}
\end{aligned}
$$

CS power, required for the gas compression of volume $q_{p}$, is calculated by the formula

$$
N=\xi \frac{z R}{m} q_{p} T_{1}\left[\left(\frac{p_{2}}{p_{1}}\right)^{m / \eta_{p o l}}-1\right],
$$

or

$$
N=\xi \frac{z R}{m} q_{p} T_{1}\left(\varepsilon^{m / \eta_{p o l}}-1\right) .
$$

Here $q_{p}$ is the gas consumption at CS ( $\mathrm{mcm} /$ day), $T_{1}$ is the gas temperature at CS entry, $m$ is the polytrope indicator, calculated by the formula

$$
m=\left(1-\lg \frac{T_{2}}{T_{1}} / \lg \frac{p_{2}}{p_{1}}\right)^{-1}
$$

$p_{1}$ is the CS entry pressure, $p_{2}$ is the CS exit pressure, $T_{2}$ is the gas temperature at CS exit, $T_{1}$ is the gas pressure at CS entry, $\eta_{p o l}$ is the polytropic efficiency, which is defined as follows:

$$
\eta_{p o l}=\frac{m}{m-1} \frac{k-1}{k}
$$

where $k$ is the adiabatic process indicator, $\xi$ is the dimensional coefficient.

Mathematical Modeling and Computing, Vol. 5, No. 1, pp. 1-9 (2018) 
Gas quantity, used for gas compression at CS in the volume $q_{p}$, is calculated by the formula

$$
q_{n}=0.02064 \frac{\xi z R T_{1}\left(\varepsilon^{m / \eta_{\text {pol }}}-1\right)}{1.16 m \eta_{g t u} Q_{n}} q_{p}\left[\frac{3}{4}+0.025 \frac{p_{a}}{1.033 K_{3}} \sqrt{\frac{T_{1}}{288}}\right],
$$

where $Q_{n}$ is the gas net calorific value $\left(\mathrm{J} / \mathrm{m}^{3}\right), \eta_{g t u}$ is the efficiency of compressor gas turbine drive, $p_{a}$ is the atmospheric pressure (MPa), $K_{3}$ is the engine load coefficient. The formulas (19)-(21) determine the amount of fuel gas required to maintain the output pressure at a given level.

We introduce the indicator

$$
B_{i}=0.02064 \frac{\xi_{i} z R T_{1}}{1.16 m \eta_{g t u} Q_{n}}\left[\frac{3}{4}+0.025 \frac{p_{a}}{1.033 K_{3}} \sqrt{\frac{T_{1}}{288}}\right], \quad \alpha=\frac{m}{\eta_{p o l}}=\frac{k(m-1)}{k-1} .
$$

Then

$$
q_{? i}=B_{i} q_{i}\left(\varepsilon_{i}^{\alpha_{i}}-1\right) .
$$

If three CSs are involved in the operation mode of GM, then fuel gas volumes at each of them will be calculated by the formulas

$$
\begin{aligned}
q_{p 1} & =\frac{B_{1} q_{0}\left(\varepsilon_{1}^{\alpha_{1}}-1\right)}{1+B_{1}\left(\varepsilon_{1}^{\alpha_{1}}-1\right)} \\
q_{p 2} & =\frac{B_{2}\left(q_{0}-q_{p 1}\right)\left(\varepsilon_{2}^{\alpha_{2}}-1\right)}{1+B_{2}\left(\varepsilon_{2}^{\alpha_{2}}-1\right)} \\
q_{p 3} & =\frac{B_{3}\left(q_{0}-q_{p 1}-q_{p 2}\right)\left(\varepsilon_{3}^{\alpha_{3}}-1\right)}{1+B_{3}\left(\varepsilon_{3}^{\alpha_{3}}-1\right)},
\end{aligned}
$$

and the total volumes of fuel gas $q_{s n}$ will be the functions of three parameters $\varepsilon_{i}, i=1,2,3$, i.e.

$$
q_{p z}=\frac{B_{1} q_{0}\left(\varepsilon_{1}^{\alpha_{1}}-1\right)}{1+B_{1}\left(\varepsilon_{1}^{\alpha_{1}}-1\right)}+\frac{B_{2}\left(q_{0}-q_{p 1}\right)\left(\varepsilon_{2}^{\alpha_{2}}-1\right)}{1+B_{2}\left(\varepsilon_{2}^{\alpha_{2}}-1\right)}+\frac{B_{3}\left(q_{0}-q_{p 1}-q_{p 2}\right)\left(\varepsilon_{3}^{\alpha_{3}}-1\right)}{1+B_{3}\left(\varepsilon_{3}^{\alpha_{3}}-1\right)} .
$$

Just as in previous paragraph, the pressure differentials $\varepsilon_{i}, i=1,2,3$ are changing parameters. If the values of the input and output pressures are known, then formula (18) makes it possible to exclude one of the pressure differentials and substitute it into the equality (22). Therefore, the volumes of fuel gas can be considered as a function of two variables. The solution of the system of two equations with two unknowns by means of known methods allows us to determine the extreme values of the fuel gas volumes. For example, from the formula (22), we define $\varepsilon_{3}$ and substitute it into (22), then the system for finding the extremum will be

$$
\left\{\frac{\partial q_{p z}}{\partial \varepsilon_{1}}=0, \quad \frac{\partial q_{p z}}{\partial \varepsilon_{2}}=0\right.
$$

Let us note that the addition of another condition, for example, for the volume of accumulated gas in the system, will allow us to exclude one of the parameters. In this case, one-parametric task is obtained to find the extrema of the fuel gas from the pressure differential.

\section{Conclusions}

The task of optimization of main gas pipelines is multiparametric. It is reduced to the analysis of nonlinear equations systems. The obtained analytical correlations allow carrying out the analysis of optimal solutions, depending on the definition of the task and the imposed conditions. The results obtained in the work allow solving the following tasks. 
1. To analyze the influence of pressure differentials of existing CSs on the parameters of the gas transportation process.

2. Determine the influence of the distribution of fuel gas consumption by CS on the distribution of pressure and mass flow through the sections of the main gas pipeline.

3. Determine the order and power CS load, at the incomplete loading of the pipeline, on the energy costs of gas transportation according to different criteria of optimality.

[1] Bellman R. E., Dreyfus S. E. Applied Dynamic Programming. Princeton, New Jersey, Princeton university press (1962).

[2] Garliauskas A. N. Dyskretnyy princip maksimuma pri upravlenii magistralnymi gasoprovodami. Gasovaia promyshlennost. 4, 14-17 (1971), (in Russian).

[3] Sun C. K., Uraikul V., ChanCं. W., Tontiwachwuthikul P. An integrated expert system/operations research approach for optimization of natural gas pipeline operations. Engineering Applications of Artificial Intelligence. 13 (4), 465-475 (2000).

[4] Todini E., PilatiS. A gradient algorithm for the analysis of pipe networks. Computer Applications in Water Supply: Vol. 1 - System analysis and simulation. London, John Wiley \& Sons. 1-20 (1988).

[5] Rios-Mercado R.Z., Wu S., ScottL.R., Boyd E. A. A Reduction technique for natural gas transmission network optimization problems. Annals of Operations Research. 117, 217-234 (2002).

[6] KulikV.S. Gas transport through branched gas transmission system optimization algorithm. Truboprovodnyi transport: teoriia i praktika. 2, 22-25 (2014), (in Russian).

[7] Kulik V.S., Kazak A. S., Hrabov I. Yu. Optimization of operating modes of distance gas transportation systems with changing productivity. Truboprovodnyy transport: teoriia i praktika. 5. 38-42 (2015), (in Russian).

[8] Karasevych A. M., Suharev M. G., Belinskiy A. V., Tverskoy I. V., Samoilov R. V. Energoeffektivnyie rezhimy gasotransportnyh system i principy ih obespecheniia. Gazovaia promyshlennost. 1, 30-34 (2012), (in Russian).

[9] Prytula N., Frolov V., Prytula M. Optimal scheduling of operating modes of the gas transmission system. Mathematical modeling and computing. 4 (1), 78-86 (2017).

[10] Prytula N., Prytula M., Daciuk A., Gladun S., Hymko O. Optymizaciia rezhymiv roboty gazotransportnoii systemy. Visnyk Nacionalnogo universytety "Lvivska politehnika". Komputerni nauky ta informaciyni tehnologii. 694, 395-401 (2011), (in Ukrainian).

[11] Prytula N., Prytula M., Yamnych V., Daciuk A., Gladun S., Hymko O. Pro optymalni rezhymy roboty bagatonytkovyh magistralnyh gazoprovodiv. Visnyk Nacionalnogo universytetu "Lvivska politehnika". Komputerni nauky ta informaciini tehnologii. 719, 256-261 (2011), (in Ukrainian).

[12] Sardanashvili S. A. Rascietnyie metody i algoritmy (truboprovodnyj transport gaza). Moscow, FGUP Izdatielstvo «Neft i gaz» RGU nefti i gaza (2005), (in Russian).

[13] Prytula N. M., Pyanylo Ya.D., Prytula M.G. Pidzemne zberigannia gazu (matematychni modeli ta metody). Lviv, RASTR-7 (2015), (in Ukrainian). 


\title{
Аналітичні методи оптимізації параметрів роботи газових трубопроводів (газових магістралей)
}

\author{
Фролов В., П'янило Я., Притула М. \\ Центр математичного моделювання \\ Інституту прикладних проблем механіки і математики \\ ім. Я. С. Підстригача НАН Украӥни, \\ вул. Д. Дудаєва, 15, 79005, Львів, Україна; \\ Філія «Науково-дослідний інститут транспорту газу» ПАТ «УКРТРАНСГАЗ», \\ вул. Маршала Конева, 16, 61004, Харків, Україна

\begin{abstract}
Запропоновано аналітичну модель експлуатації магістрального газопроводу. Наведено результати дослідження області оптимальності за допомогою аналітичних методів. Розроблене програмне забезпечення перевірене на реальних даних. Представлено порівняльні результати моделювання та оптимізації за допомогою чисельних та аналітичних методів.
\end{abstract}

Ключові слова: газотранспортна система, оптимізачія, оптимальний режим, компресорна станиіл.

2000 MSC: $76 \mathrm{~N} 25,49 \mathrm{~J} 20$

УдК: $622.692 .4+622.691 .24$ 